\title{
Kinetics and thermodynamics of cottonseed oil extraction
}

\author{
By Devesh K. Saxena, ${ }^{a *}$ S. K. Sharma, ${ }^{b}$ and S. S. Sambi ${ }^{\mathrm{c}}$ \\ ${ }^{a}$ Research Scholar,University School of Chemical Technology, Guru Gobind Singh Indraprastha \\ University, Kashmere gate, Delhi-110403. \\ ${ }^{\mathrm{b}}$ Assistant Professor, University School of Chemical Technology, Guru Gobind Singh Indraprastha \\ University, Kashmere gate, Delhi-110403. \\ ${ }^{c}$ Professor \& Dean, University School of Chemical Technology, Guru Gobind Singh Indraprastha \\ University, Kashmere gate, Delhi-110403. \\ ( ${ }^{*}$ Corresponding author: devesh_saxena@ rediffmail.com)
}

\section{RESUMEN}

Cinética y termodinámica de la extracción del aceite de algodón.

El n-hexano derivado del petróleo es comercialmente usado en plantas de extracción con disolventes debido a su mayor eficiencia de extracción, a pesar de que está calificado como altamente tóxico y peligroso. El presente estudio está basado en el uso de etanol, disolvente mucho más seguros y no tóxico, y n-hexano en la extracción de aceite de algodón. Los datos de extracción fueron obtenidos variando la temperatura, la proporción sólido-disolvente y el tamaño de partícula, para comparar la eficiencia de extracción del etanol y del hexano. Los datos muestran que casi la misma cantidad de extracción es posible para ambos disolventes a la proporción más alta de sólido-disolvente. Este estudio es capaz de establecer que las cinéticas de extracción de aceite siguen un mecanismo de reacción de segundo orden. El análisis termodinámico de los datos mostró que $\Delta \mathrm{H}^{\circ}$ and $\Delta \mathrm{S}^{\circ}$ son positivas, y $\Delta \mathrm{G}^{\circ}$ es negativa, indicando que el proceso de extracción es endotérmico, irreversible y espontáneo.

PALABRAS-CLAVE: Algodón - Cinéticas - Etanol - Extracción de aceite - n-Hexano - Termodinámica.

\section{SUMMARY}

Kinetics and thermodynamics of cottonseed oil extraction.

Petroleum derived $n$-hexane is commercially used in solvent extraction plants due to its higher extraction efficiency in spite of the fact that it is graded as highly toxic and hazardous. The present study is based on the use of both a much safer and non toxic solvent ethanol and n-hexane for the extraction of oil from cottonseed. The extraction data were obtained by varying temperature, solvent-solid ratio and particle size, to compare the extraction efficiency of both ethanol and $n$-hexane. The data show that nearly the same amount of extraction is possible at a higher solvent-solid ratio for both the solvents. This study has established that the kinetics of oil extraction follows a second order reaction mechanism. The thermodynamic analysis of the data shows that both $\Delta \mathrm{H}^{\circ}$ and $\Delta \mathrm{S}^{\circ}$ are positive, and $\Delta \mathrm{G}^{\circ}$ is negative indicating that the extraction process is endothermic, irreversible, and spontaneous.

KEY-WORDS: Cottonseed - Ethanol - n-Hexane Kinetics - Oil extraction - Thermodynamics.

\section{INTRODUCTION}

Cotton has been grown globally for centuries mainly to meet the basic requirements of cotton fabrics, whereas cottonseed left after the removal of the cotton fiber is also a valuable by-product. Cottonseed is a rich source of oil and protein and India is the second largest producer of cotton seed which is the sixth largest source of oil available in the world (Shekhar, 2004). Cottonseed oil is important for food processing due its distinct properties. It is rich in antioxidant tocopherol (Vitamin-E) which resists rancidity development and contributes to its stability, giving the product a longer shelf life. It is described as a "naturally hydrogenated oil" as it contains sufficient natural palmitic, stearic and mysteric acids. Due to the presence of unsaturated oleic, linoleic and linoleinic fatty acids it is also known as a "Heart Healthy Oil". It is used as salad oil, for the frying of potato and corn chips, in seafood and oriental foods. However, it is now being used in a much wider range of processed foods including cereals, bread and snack foods (Brien et al., 2005). It also has non food applications such as in bio-diesel production (Junfeng et al., 2010), and as a lubricant additive (Ertugrul et al., 2004).

The oil can be obtained from cottonseeds by mechanical pressing, solvent extraction, and supercritical fluid extraction (Liauw et al., 2008; Bhattacharjee et al., 2007; List et al., 1984). The quality of oil extracted by mechanical pressing or squeezing in an expeller press is inferior and has a limited recovery of only $94-95 \%$. Though the supercritical extraction of flaked cottonseed with carbon dioxide at 323-353K and 8,000-15,000psi pressure yields a better quality oil with less refining loss, operating and investment costs are very high compared to those for conventional solvent extraction or mechanical pressing.

The solvent $n$-hexane has been extensively used for oil extraction from oilseeds because of its low boiling point of 336.16-342.26K, high stability, low corrosiveness, low greasy residual effect, better odor and improved flavor for milled products 
(Johnson and Lusas, 1983; Becker, 1978). It is listed as a hazardous air pollutant by the US Clean Air Act since it can react with other pollutants to produce ozone and photochemical oxidants (Wan et al., 1995a; Hanmoungjai et al., 2000) and its use in oilseed extraction plants can adversely affect workers' central nervous system (Becker, 1978; Johnson and Lusas, 1983; Lusas et al., 1991; Gandhi et al., 2003). The control of its emission levels in extraction plants requires the installation of additional control equipment at additional costs (Conkerton, et al., 1995). Seth (2007) has reported that the use of n-hexane in small capacity plants makes the process expensive because of high operating losses (typically ranging from 0.75 to 7.5 L/MT of processed seeds). Further, n-hexane, being a petroleum product, faces occasional scarcity and fluctuation in price depending on the supply and demand of gasoline.

The cottonseed oil extraction industry is seeking a safer alternative solvent to eliminate the emissions of $n$-hexane into the atmosphere as well as potential traces of $n$-hexane in both the refined edible oils and the meal. The prevention of food adulteration act in India has ruled that the oil obtained by solvent extraction shall not contain more than 5ppm of $n$-hexane and the meal should not contain more than 10ppm (PFA Act, 1954). It is, however, desirable that hexane be removed completely from the meal. Most of the n-hexane extraction units suffer from the difficulty of totally removing residual solvents from the meal (Eskin et al., 1995).

The extraction of oil with aqueous solutions (acidic or alkaline at 318 to $258 \mathrm{~K}$ ) has been reported in the literature as an alternative to organic solvents (Hagenmaier et al., 1973; Kim, 1989; Hanmoungjai et al., 2000). However, due to the low selectivity of aqueous solutions for lipids, the simultaneous extraction of proteins, carbohydrates and other compounds also occurs in this case. Aqueous extraction is also limited by (i) the lower efficiency of oil extraction, (ii) the need for an additional de-emulsification step to recover the oil and (iii) the production of an aqueous effluent which requires further treatment (Hanmoungjai et al., 2000). Heptane and isohexane (Wan et al., 1995a; Wan et al., 1995b; Conkerton, et al., 1995, Kuk and Hron,1998), methylpentanes (Ayer and Scott, 1951), acetone (Frampton et al., 1967; Kuk et al., 2005) and alcohols (Abraham et al., 1988; Hron et al., 1994; Sineiro et al., 1998) are also reported as other solvents besides aqueous for oil extraction.

Isopropanol and ethanol are the most promising solvents for oil extraction from cottonseed (Lusas et al., 1991; Abraham et al., 1988; Hron et al., 1994, Bhowmick, et al., 2003), sunflower seed (Sineiro et al., 1998), soybean (Baker and Sullivan, 1983), Quercus suber L. fruits (Ferreira-Dias et al., 2003), and Neem (Liauw et al., 2008). Ethanol has, however, emerged as a better alternative solvent since its cost is low and it can be produced from a large variety of biological materials through fermentation. Although flammable (flash point $=$ $282.06 \mathrm{~K}$; ignition temperature $=698.16 \mathrm{~K})$, it is rated as safe (Hron et al., 1994), non-toxic and has lower handling risks compared to n-hexane (flash point $=250.16 \mathrm{~K}$; ignition temperature $=498.16 \mathrm{~K}$ ). Ethanol provides a much safer work environment in extraction plants since its threshold limit value of the time weight average is $1000 \mathrm{ppm}$ as compared to $50 \mathrm{ppm}$ for n-hexane [NIOSH, 2007].

The use of ethanol as an extraction solvent has the advantage of eliminating the toxicity problems in the meal for animal feedstuff caused by $n$-hexane. Abraham, et al. (1988) have reported that $95 \%$ oil could be extracted with ethanol from cottonseed, and the resulting alcoholic miscella could be easily refined with caustic to produce an acceptable oil (Hron and Koltun, 1984). The use of alcohols to extract oil from seeds is not new. Japanese workers, among others, reported the use of aqueous ethanol to extract oil from soybeans as early as 1932 (Hron et al., 1994). However, the process could not be commercialized for several reasons. Cottonseed, like other oilseeds, is pre-treated before extraction to release the oil. The pretreatment operations include de-hulling, cracking, flaking, thermal treatment etc. (Hoffman et al., 1989).

The extraction rate of oil is a major influential factor for designing a large-scale solvent extraction system. Normally, extraction rate depends on the nature of the solvent and the oil, reaction time between solvent and seeds, temperature of the process, particle size of the meal, and solvent-solid ratio. Coats and Wingard (1950) observed that the oil extraction rate was largely dependent on particle size. Seth et. al, (2007) reported that oil from cracked particles (grits) of soybeans, cottonseed, flaxseed, and peanuts could be extracted more easily compared to flakes of equivalent thickness.

Keeping the literature findings in mind, ethanol and n-hexane were used in the present study as solvents for the extraction of oil from cottonseeds to generate data for the study of the kinetics and thermodynamics of the extraction process. The data were generated by varying parameters such as solvent-solid ratio (SR), temperature, and particle size (PS). The results obtained for both the solvents are compared to establish the advantages of ethanol as an alternative to n-hexane.

\section{MATERIALS AND METHODS}

\subsection{Materials}

\section{Seed Preparation}

For the purpose of this study, acid delinted cottonseeds of Gossypium Hirsutum (P8-6 variety) were obtained from the Indian Agricultural Research Institute, Pusa, N. Delhi. The seeds were de-hulled in the laboratory using a mixer grinder. The dehulled seeds were dried in a vacuum oven at $318 \mathrm{~K}$ 
to remove moisture and then segregated into three fractions $A, B$, and $C$ using standard sieves. The average particle size of the three fractions $A, B$, and C were $0.6,1.6$ and $2.4 \mathrm{~mm}$ respectively. The dehulled seeds were found to contain $36.87 \%$ oil on a dry solid basis. The oil percentage was determined by an exhaustive extraction method using hexane in a soxhlet apparatus.

\section{Solvents}

Both n-Hexane and Ethanol of L.R grade from Fisher were redistilled and used as solvents.

\subsection{Methods}

\section{Oil Testing}

A) Solid Sample: The oil content in the solid sample was determined according to the method described in Appendix F of IS: 7847-1968 of the Bureau of Indian Standards [IS: 7847-1968].

B) Liquid Sample: To estimate the oil content in a liquid sample the oil percentage was determined based on the change in density of the sample. A Mettler Toledo density meter, Model DE-45 Delta Range was used to record the change in density of up to 4 decimal places. First, calibration curves ware prepared using raw cottonseed oil extracted by $n$-hexane and ethanol respectively. A known quantity of oil was dissolved in the same solvent at different dilutions, the density of each dilution was measured and the calibration curve density vs oil concentration (gm oil/L solvent) was prepared. To determine the oil content in the liquid phase, the density of the clear liquid portion separated after centrifugation was obtained. The oil content in the sample was calculated using the calibration curve. For few representative clear liquid samples, the results were cross-checked for oil content by evaporating the solvent in a vacuum oven to obtain solvent-free oil (Conkerton et al., 1995).

\section{Oil extraction}

The weighed quantity of cottonseed samples taken in the airtight $30 \mathrm{ml}$ plastic bottles and the solvent bottle were kept overnight in a constant temperature incubator to attain the desired uniform temperature. The measured quantity of solvent was then mixed with the seed sample in the bottles for oil extraction. After mixing, the bottles were closed airtight and placed immediately in the shaking incubator. The study was conducted for a period of three hours and one plastic bottle was taken out after a specified period of $1,5,10,20,40$, 60, 120 and 180 minutes; the supernatant liquid (slightly hazy) was removed from the plastic bottle and centrifuged at 9000rpm for 5 minutes. The clear transparent liquid obtained after centrifuge was removed for oil determination. Extraction was conducted at four temperatures i.e. $288,298,308$, and $318+1 \mathrm{~K}$, three solvent-solid ratios $(5: 1,10: 1$ and 15:1) and three particle sizes i.e.. A, B and C. Percentages of oil extracted was calculated using Eq.1. Experiments were duplicated and the average value was taken to ensure accuracy and the results were expressed on a dry basis.

$$
\text { Percent Oil Extracted }(\%)=\frac{C_{t} \times V}{w_{0}} \times 100
$$

Where: $C_{t}=$ Oil concentration in solvent at any time, $\mathrm{t}(\mathrm{g} / \mathrm{L})$

(L)

$\mathrm{V}=$ Volume of solvent mixed with seed sample

$\mathrm{w}_{\mathrm{o}}=$ Weight of total oil present in the seed sample (g)

\section{RESULTS AND DISCUSSION}

\subsection{Effect of Particle Size}

The oil extraction was carried out with the seed sizes $A(0.6 \mathrm{~mm}), B(1.6 \mathrm{~mm})$ and $C(2.4 \mathrm{~mm})$ using both the solvents at $308 \mathrm{~K}$ and solvent-solid ratio 10:1 for three hours to study the effect of particle size. The results are shown in Figure 1. It may be seen from Figure 1 that the oil extracted in $3 \mathrm{hrs}$ is $85.24,49.36$ and $40.82 \%$ from the seeds of sizes A, $B$ and $C$ with $n$-hexane and $81.75,48.07$ and 40.22 $\%$ from the seeds of sizes $A, B$ and $C$ with ethanol respectively under similar conditions. The lower rate of extraction from larger size particles $B$ and $C$ can be attributed to both the lower surface area per unit weight and higher resistance to extraction due to the longer path the solvent has to travel to leach out the oil as compared to A size particles.

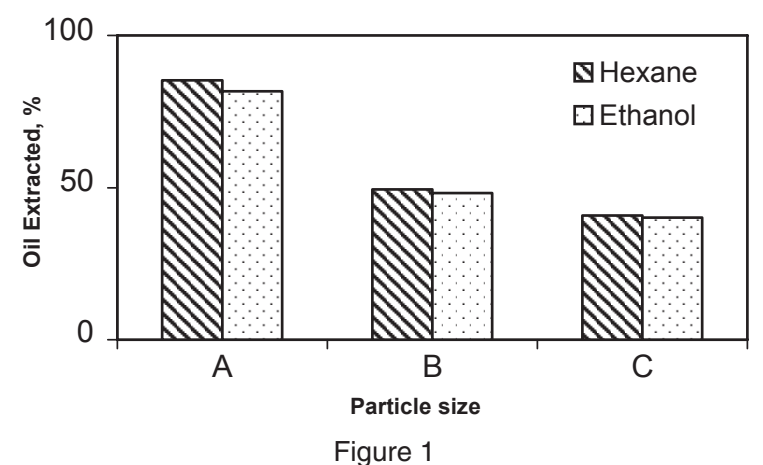

Effect of Particle Size on Oil Extracted at 308K and SR 10:1.

\subsection{Effect of Solvent-Solid Ratio (SR)}

In the present work to study the effect of solventsolid ratio (SR) on oil, extraction experiments were conducted at $308 \mathrm{~K}$ with Size-A by varying SR. The SR of $5: 1,10: 1$ and $15: 1$ were used during the study. It can be seen from Figure 2 that by increasing the SR the amount of oil extracted increased. The extraction of oil at the SR of 5:1 was very low, whereas at the other two ratios of 10:1 and 15:1 the oil extraction was better. In the case 


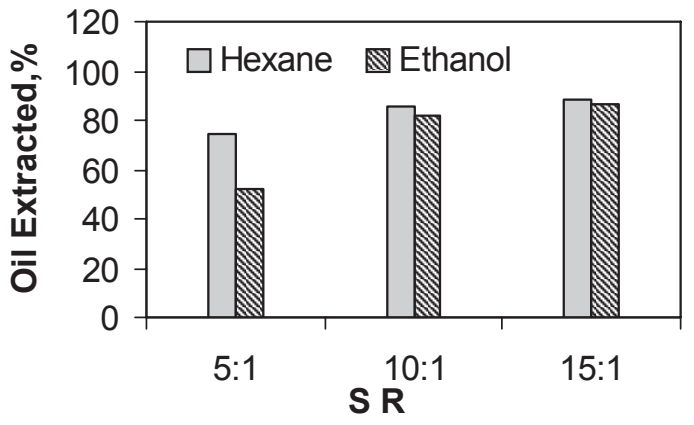

Figure 2

Effect of Solvent to solid Ratio on Oil Extracted at $308 \mathrm{~K}$ from Particle Size-A.

of extraction with ethanol at the SR of $5: 1$ the oil extraction was only $57.71 \%$, whereas at the SR of $10: 1$, it was $82.31 \%$ and at the SR of $15: 1$, it was $86.42 \%$. The lower oil extraction at the SR of $5: 1$ can be explained by the fact that the solubility of oil in ethanol may restrict the oil extraction from the seed near the saturation point of oil in ethanol. At higher SR the efficiency of oil extraction with ethanol was found to be comparable with $n$-hexane. At the SR of $10: 1$ and $15: 1$ the extraction was $85.24 \%$ and $88.71 \%$ with n-hexane and $82.31 \%$ and $86.42 \%$ with ethanol. Slightly lower oil extraction with ethanol can be attributed to the solubility of cottonseed oil in ethanol as compared to solubility in n-hexane.

\subsection{Effect of Extraction Temperature}

The studies were conducted at SR of 10:1 and particle size-A by varying the temperature from 288 to $318 \mathrm{~K}$ to see its effect on the oil extraction process. It was found that an increase in temperature has a direct effect on the amount of oil extracted as shown in Figure-3. It may be seen from Figure-3 that the amount of oil extracted with n-hexane increased from $58.20 \%$ to $92.84 \%$ as the extraction temperature increased from 288 to $318 \mathrm{~K}$, whereas the increase in extraction was from $48.08 \%$ to $93.84 \%$ as the temperature increased from 288 to $318 \mathrm{~K}$, when ethanol was used as the solvent. This increase may be due to the increase

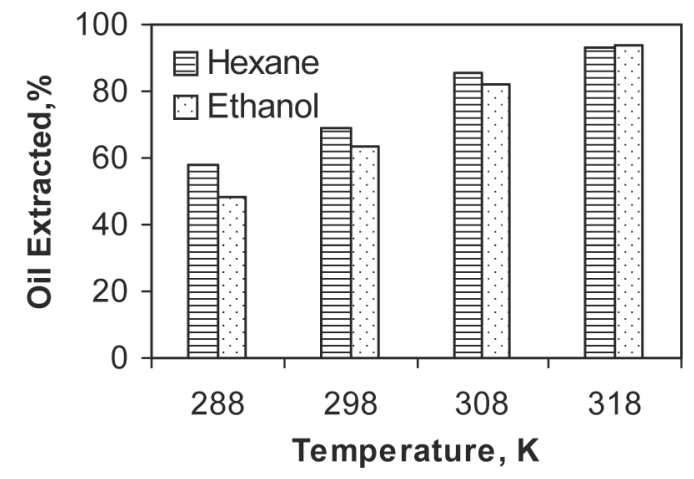

Figure 3

Effect of Temperature on Oil Extraction at SR 10:1,Particle Size-A in $3 \mathrm{Hrs}$. in oil solubility in the solvent at a higher temperature and a decrease in viscosity of the solution resulting in lower diffusion resistance in the pores of the particle.

\subsection{Effect of Extraction Time}

The extraction of oil from cottonseeds was carried out with n-hexane and ethanol for a period of 3 hours at $308 \mathrm{~K}$ and at SR of 10:1 and the data were plotted in Figure-4. It can be seen that the extraction of oil increases with time and the rate of extraction is initially high and then tapers off. The oil extraction in the first hour reached $77.28 \%$ with n-hexane and $75.16 \%$ with ethanol at $308 \mathrm{~K}$. After this there is a small increase in oil extraction and the total oil extracted in 3 hours is $85.25 \%$ and $81.75 \%$ with $n$-hexane and ethanol respectively at $308 \mathrm{~K}$. The initially high rate of oil extraction may be because of the dissolution and the scrubbing of the oil available on the surface and the later slow extraction rate may be attributed to the diffusion of the remaining oil into the solution as supported by the study of Rakotondramasy, et al. (2007).

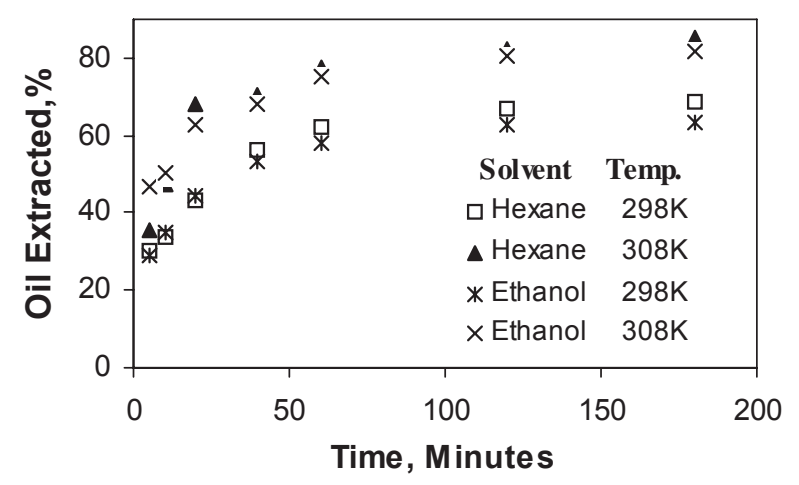

Figure 4

Effect of Time on Oil Extracted at SR 10:1 from Particle Size- A.

\subsection{Kinetics}

Various studies have been reported to describe the mechanism and kinetics of the extraction processes. A second order reaction kinetics for the solid-liquid extraction process has been proposed by most of the researchers (Wiese et al., 1987; Meziane, et al., 2006; Meziane, et al., 2008; Rakotondramasy, et al. 2007, Sepidar et al. 2009, Wenjuan et al., 2010). It is typical of a second order process to take place in two stages. First, the major part of the solute gets extracted quickly because of the dissolution and scrubbing of the surface oil caused by the higher driving force of the fresh solvent and in the next stage where the extraction rate is slowed down by the low diffusion of the remaining oil.

The rate of dissolution of the oil into the solution can be described by the following second order rate equation:

$$
\frac{d C_{t}}{d t}=k\left(C_{e}-C_{t}\right)^{2}
$$


Where:

$\mathrm{k}=$ The second-order extraction rate constant (L/g-min)

$\mathrm{C}_{\mathrm{e}}=$ The concentration of oil in the solution at equilibrium $(\mathrm{g} / \mathrm{L})$

$C_{t}=$ The concentration of oil $(g / L)$ in the solution at any time, $\mathrm{t}$ (min)

Now considering the initial condition at $t=0, C_{t}$ $=0$, the integrated second-order rate law for the extraction obtained could be written as

$$
C_{t}=\frac{C_{e}^{2} k t}{1+C_{e} k t}
$$

The extraction rate Eq.(3) can be rearranged as follows:

$$
\frac{C_{t}}{t}=\frac{k C_{e}^{2}}{1+C_{e} k t}
$$

Now, when $t \rightarrow 0$, the LHS of Eq.(4) will be initial extraction rate, $E_{i}$, and the denominator of $\mathrm{RHS}$ will reach 1.0 thus Eq.(4) reduces to Eq.(5)

$$
E_{i}=k C_{e}^{2}
$$

Thus Eq.(4) after combining with Eq.(5), the rearrangement would yield the following linear form:

$$
\frac{t}{C_{t}}=\frac{1}{E_{i}}=\frac{t}{C_{e}}
$$

The initial extraction rate, $E_{i}$, the concentration of oil in the solution at equilibrium, $C_{e}$ and the second order extraction constant, $k$, can be calculated from the experimental data by plotting $t / C_{t}$ vs. $t$. The experimental data are recorded using an MS-excel spread sheet and the estimated results at SR 10:1 to $15: 1$ and temperatures from 288 to $318 \mathrm{~K}$ are given in Table 1. The results show that for all cases, the value of the regression coefficient $\left(R^{2}\right)$ lies between 0.98-0.99. This indicates that the data are well described by second order kinetics. Further, it can be seen that the initial rate of extraction is not appreciably affected by SR but is largely affected by temperature.

\subsection{Thermodynamics}

Thermodynamic considerations of an extraction process are necessary to conclude whether the process is spontaneous or not. The Gibbs free energy change $\left(\Delta G^{\circ}\right)$ is an indication of the spontaneity of a chemical reaction and therefore is an important criterion for spontaneity. Reactions occur spontaneously at a given temperature if $\Delta G^{\circ}$ is a negative quantity. Gibbs free energy $\left(\Delta G^{\circ}\right)$, enthalpy change $\left(\Delta H^{\circ}\right)$ and entropy change $\left(\Delta S^{\circ}\right)$ are calculated using the following equations:

$$
\begin{gathered}
K_{e}=\frac{C_{e}}{C_{s}} \\
\Delta G^{\circ}=-R \ln K_{e} \\
\Delta G^{\circ}=\Delta H^{\circ}-T \Delta S^{\circ} \\
\ln K_{e}=-\frac{\Delta H^{\circ}}{R T}+\frac{\Delta S^{\circ}}{R}
\end{gathered}
$$

\begin{tabular}{|c|c|c|c|c|c|c|}
\hline Solvent & $\begin{array}{c}\text { SR } \\
(\mathrm{ml} / \mathrm{g})\end{array}$ & $\begin{array}{c}\text { Temp., } \\
\text { (K) }\end{array}$ & $\begin{array}{c}C_{e}, \\
\text { (g/L) }\end{array}$ & $\begin{array}{c}k, \\
(L / g-\min )\end{array}$ & $\begin{array}{c}E_{i} \\
\text { (g/L-min) }\end{array}$ & $R^{2}$ \\
\hline \multirow{8}{*}{ N-Hexane } & $10: 1$ & 288 & 22.675 & $4.13 \times 10^{-3}$ & 2.124 & 0.99 \\
\hline & $10: 1$ & 298 & 26.455 & $4.29 \times 10^{-3}$ & 3.003 & 0.99 \\
\hline & $10: 1$ & 308 & 32.362 & $4.56 \times 10^{-3}$ & 4.775 & 0.99 \\
\hline & $10: 1$ & 318 & 34.843 & $4.66 \times 10^{-3}$ & 5.656 & 0.99 \\
\hline & $15: 1$ & 288 & 17.668 & $4.60 \times 10^{-3}$ & 1.435 & 0.98 \\
\hline & $15: 1$ & 298 & 20.703 & $6.44 \times 10^{-3}$ & 2.762 & 0.99 \\
\hline & $15: 1$ & 308 & 22.573 & $8.04 \times 10^{-3}$ & 4.098 & 0.99 \\
\hline & $15: 1$ & 318 & 23.041 & $11.15 \times 10^{-3}$ & 5.917 & 0.99 \\
\hline \multirow{8}{*}{ Ethanol } & $10: 1$ & 288 & 17.921 & $5.61 \times 10^{-3}$ & 1.802 & 0.99 \\
\hline & $10: 1$ & 298 & 24.331 & $5.70 \times 10^{-3}$ & 3.377 & 0.99 \\
\hline & $10: 1$ & 308 & 30.864 & $5.85 \times 10^{-3}$ & 5.577 & 0.99 \\
\hline & $10: 1$ & 318 & 35.971 & $5.96 \times 10^{-3}$ & 7.722 & 0.99 \\
\hline & $15: 1$ & 288 & 15.847 & $6.06 \times 10^{-3}$ & 1.520 & 0.99 \\
\hline & $15: 1$ & 298 & 17.668 & $7.08 \times 10^{-3}$ & 2.211 & 0.99 \\
\hline & $15: 1$ & 308 & 21.739 & $8.45 \times 10^{-3}$ & 3.995 & 0.99 \\
\hline & $15: 1$ & 318 & 24.213 & $12.19 \times 10^{-3}$ & 7.148 & 0.99 \\
\hline
\end{tabular}

Where $C_{s}$ is the concentration of oil in solid phase at equilibrium and could be obtained by material balance. $R$ is the ideal gas constant (8.314 $\mathrm{J} \mathrm{mol}^{-1} \mathrm{~K}^{-1}$ ), and $T$ is the temperatura (K). Eq. 10

Table 1

Kinetics Parameter of Cotton Seed oil extraction using $n$-hexane and ethanol 
is a Van't Hoff relation and the plot of $\ln K_{\mathrm{e}}$ Vs. $I / T$ is used to find the values of $\Delta H^{\circ}$ and $\Delta S^{\circ}$ from the slope and the intercept. $\Delta G^{\circ}$ and $\Delta H^{\circ}$ are in $\mathrm{J} / \mathrm{mol}$, $\Delta S^{\circ}$ is in $\mathrm{J} / \mathrm{mol} \mathrm{K}$.

The values of $K_{e}, \Delta G^{\circ}, \Delta H^{\circ}$ and $\Delta S^{\circ}$ for the extraction of cottonseed oil using n-hexane and ethanol as solvents were calculated using Eqs. (7) and (10) are given in Tables 2 and 3 . The values of $\Delta G^{\circ}$ calculated were found negative for the oil extraction from cottonseed at all temperatures for both solvents and decreased from -11531.86 to $-18556.50 \mathrm{~J} / \mathrm{mol}$ for $\mathrm{n}$-hexane and -10419.74 to $-20962.73 \mathrm{~J} / \mathrm{mol}$ for ethanol. The negative value for the Gibbs free energy for oil extraction from cottonseed confirm that this process is feasible and spontaneous and that the degree of spontaneity of the extraction increases with increasing temperatures as $\Delta G^{\circ}$ becomes more negative. The decrease in the negative value of $\Delta G^{\circ}$ with an increase in temperature indicates that the oil extraction from cottonseed becomes more favorable at higher temperatures. The values of $\Delta H^{\circ}$ calculated from the plot of $\ln K_{e}$ versus $1 / T$ were in the range of 43212.84 to $57330.85 \mathrm{~J} / \mathrm{mol}$ and 84511.81 to 85758.91 for n-hexane and ethanol, respectively. The value of $\Delta H^{\circ}$ was positive, indicating that the extraction is endothermic and requires energy during the process. The positive value of entropy indicates that the process is irreversible.

\subsection{Properties of oil extracted by the two solvents}

The oil extracted by $n$-hexane and ethanol was tested for various parameters and the results are reported in Table 4. It may be seen that there is not much variation between the quality of the oil extracted by $n$-hexane or ethanol except that the color of the oil extracted by ethanol is slightly darker than the oil extracted by $\mathrm{n}$-Hexane. This indicates that ethanol is a good solvent for oil. Acid value,

Table 2

Equilibrium Constant of Cotton Seed oil extraction using $n$-hexane and ethanol

\begin{tabular}{|c|c|c|c|c|}
\hline \multirow{3}{*}{$\mathrm{T}(\mathrm{K})$} & \multicolumn{4}{|c|}{ Equilibrium constant (Ke) } \\
\hline & \multicolumn{2}{|c|}{$S R=10: 1$} & \multicolumn{2}{|c|}{$S R=15: 1$} \\
\hline & n-Hexane & Ethanol & n-Hexane & Ethanol \\
\hline 288 & 123.484 & 77.606 & 125.183 & 92.195 \\
\hline 298 & 186.721 & 146.770 & 245.298 & 125.183 \\
\hline 308 & 485.074 & 354.997 & 495.198 & 343.395 \\
\hline 318 & 1117.373 & 2548.409 & 651.933 & 2776.257 \\
\hline
\end{tabular}

Table 3

Thermodynamic parameters of Cotton Seed oil extraction using $\mathrm{n}$-hexane and ethanol

\begin{tabular}{|c|c|c|c|c|c|}
\hline Solvent & $\begin{array}{c}\text { SR } \\
(\mathrm{ml} / \mathrm{g})\end{array}$ & $\begin{array}{c}\text { Temp } \\
\text { (K) }\end{array}$ & $\begin{array}{c}\Delta G^{\circ} \\
(\mathrm{J} / \mathrm{mol})\end{array}$ & $\begin{array}{c}\Delta H^{\circ} \\
(\mathrm{J} / \mathrm{mol})\end{array}$ & $\begin{array}{c}\Delta \boldsymbol{S}^{\circ} \\
(\mathrm{J} / \mathrm{mol})\end{array}$ \\
\hline \multirow[t]{8}{*}{ n-Hexane } & $10: 1$ & 288 & -11531.86 & 57330.85 & 237.79 \\
\hline & & 298 & -12956.76 & & \\
\hline & & 308 & -15836.22 & & \\
\hline & & 318 & -18556.50 & & \\
\hline & $15: 1$ & 288 & -11564.58 & 43212.84 & 190.65 \\
\hline & & 298 & -13632.78 & & \\
\hline & & 308 & -15889.11 & & \\
\hline & & 318 & -17132.01 & & \\
\hline \multirow[t]{8}{*}{ Ethanol } & $10: 1$ & 288 & -10419.74 & 85758.91 & 331.34 \\
\hline & & 298 & -12360.28 & & \\
\hline & & 308 & -15036.79 & & \\
\hline & & 318 & -20736.33 & & \\
\hline & $15: 1$ & 288 & -10832.19 & 84511.81 & 327.35 \\
\hline & & 298 & -11966.13 & & \\
\hline & & 308 & -14951.69 & & \\
\hline & & 318 & -20962.73 & & \\
\hline
\end{tabular}


Table 4

Comparison of quality parameters of oil extracted by $n$-hexane and ethanol

\begin{tabular}{|c|c|c|c|}
\hline \multirow{2}{*}{ S.No. } & \multirow{2}{*}{ Parameters } & \multicolumn{2}{|c|}{ Solvent } \\
\hline & & n-Hexane & Ethanol \\
\hline 1 & Color & Brown & Dark Brown \\
\hline 2 & Specific gravity $\mathrm{g} / \mathrm{L}$ & 0.9182 & 0.9202 \\
\hline 3 & Refractive Index at $313 \mathrm{~K}$ & 1.4641 & 1.4647 \\
\hline 4 & Acid value & 0.37 & 0.52 \\
\hline 5 & lodine value & 106.8 & 107.2 \\
\hline 6 & Saponification Value & 194.5 & 197.8 \\
\hline 7 & Gossypol (\%) & 0.27 & 0.63 \\
\hline
\end{tabular}

which is the indicator of free fatty acids present in the oil, is slightly higher in the oil extracted by ethanol. lodine value, which is the indication of the unsaturation level of the oil, is nearly the same in both the oils and saponification value, which indicates the average molecular weight of triglycerides of the oil, is also comparable. In a nutshell, the quality of the oil extracted by ethanol is comparable to the quality of the oil extracted by $n$-hexane except for the gossypol content, which can be practically completely removed during the refining process of the oil before actual consumption.

\section{CONCLUSION}

The study concludes that ethanol can be considered as an alternative solvent to n-hexane for oil extraction at the SR of 10:1 and 318K where the efficiency of extraction is comparable to that of $n$-hexane. The quality of oil after refining is also acceptable for food preparations. The extraction data are well described by second order kinetics. The initial rate of extraction is not appreciably affected by the SR but is largely affected by temperature. The positive value of $\Delta H^{\circ}$ indicates that the extraction is endothermic and requires an input of energy during the extraction process. The positive value of entropy indicates that the extraction process is irreversible. The negative value of the Gibbs free energy for the oil extraction from cottonseed confirms that the process is spontaneous and feasible. The oil extraction from cottonseed is favorable at higher temperatures.

\section{ACKNOWLEDGEMENT}

The authors gratefully acknowledge the facilities provided for research by the Guru Gobind Singh Indraprashtha University, Delhi, India. The authors are also thankful to Dr. Ambarish Kumar Sharma, Sr. Scientist, Dept. of Genetics, Indian Agricultural Research Institute, Pusa, N Delhi and his staff for providing the special variety of seed developed by them for research.

\section{REFERENCES}

Abraham G, Hron RJ, Koltun SP. 1988. Modeling the solvent extraction of oilseeds. J. Am. Oil Chem. Soc. 65, 129-135.

Ayers AL, Scott CR. 1951. Cottonseed oil extraction with normal Hexane and Methylpentanes. J. Am. Oil Chem. Soc. 28, 348-351.

Baker EC, Sullivan DA. 1983. Development of a pilotplant process for the extraction of soy flakes with aqueous isopropyl alcohol. J. Am. Oil Chem. Soc. 60, 1271-1277.

Becker W. 1978. Solvent extraction of soybean. J. Am. Oil Chem. Soc. 55, 754-761.

Bhattacharjee P, Singhal RS, Tiwari SR. 2007. Supercritical carbon dioxide extraction of cottonseed oil. J. Food Eng. 79, 892-898.

Bhowmick DN, Rebello D. 2003. Improved Utilization of cottonseed meal by Isopropanol Extraction, http:// www.vurabalu.com/masterssponsor.htm.

Brien RDO, Wakelyn PJ. 2005. Cottonseed Oil: An oil for trans-free options. J. Food Technol. 16, 677-679.

Coats HB, Wingard MR. 1950. Solvent extraction-III: The effect of particle size on extraction rate. J. Am. Oil Chem. Soc. 27, 93-96.

Conkerton EJ, Wan PJ, Richard OA. 1995. Hexane and heptane as extraction solvents for cottonseed: a laboratory-scale study. J. Am. Oil Chem. Soc. 72, 963-965.

Ertugrul D, Filiz K. 2004. Using of Cottonseed Oil as an environmentally accepted Lubricant additive. Energy Sources, part A, Recovery, Utilization and Environmental Effects 26, 611-625.

Eskin NAM, Akomas O, Latta M. 1995. A study of gossypol reduction by choline and ethanolamine using a model system. Food Chemistry 52, 43-46.

Frampton VL, Pepperman AB, Joseph S, King WH. 1967. Countercurrent extraction of Raw Cottonseed Flakes with the Acetone-Hexane-Water Azeotrope. J. Agr. Food Chem. 15, 790-797.

Ferreira-Dias S, Valente DG, Abreu JMF. 2003. Comparision between ethanol and hexane for oil extraction from Quercus suber $L$ fruits. Grasas y Aceites 54, 378-383.

Gandhi AP, Joshi KC, Jha K, Parihar VS, Srivastav DC, Raghunadh P, Kawalkar J, Jain SK, Tripathi RN. 2003. Studies on alternative solvents for the extraction of oil-I soybean. Int. J. of Food Sci. Technol. 38, 369-375.

Hagenmaier R, Cater CM, Mattil KF. 1973. Aqueous processing of fresh coconuts for recovery of oil and coconut skim milk. J. Food Sci. 38, 516-518. 
Hanmoungjai P, Pyle L, Niranjan K. 2000. Extraction of rice bran oil using aqueous media. J. Chem. Technol. Biotechnol. 75, 348-352.

Hoffman G. 1989. The Chemistry and Technology of Edible Oils and Fats and their High Fat Products, Academic Press, New York. pp 63-64.

Hron RJ, Koltun SP. 1984. An aqueous ethanol extraction process for cottonseed. J. Am. Oil Chem. Soc. 61, 1457-1460.

Hron RJ Sr., Kuk MS, Abraham G, Wan PJ. 1994. Ethanol extraction of oil, gossypol and aflatoxin from cottonseed. J. Am. Oil Chem. Soc. 71, 417-421.

IS: 7847-1968, Specification for Edible Cottonseed Flour (Expeller Pressed) Bureau of Indian Standard.

Johnson LA, Lusas EW. 1983. Comparison of alternative solvents for oil extraction. J. Am. Oil Chem. Soc. 60, 229-241.

Junfeng Q, Zhi Y, Haixian S. 2010. Cogeneration bio diesel and non toxic cottonseed meal from cottonseed processed by two phase solvent extraction. Energy Conversion and Management, article in press

Kim SH. 1989. Aqueous extraction of oil from palm kernel. J. Food Sci. 54, 491-492.

Kuk MS, Tetlow R, Dowd MK. 2005. Cotton seed extraction with mixture of acetone and hexane. J. Am. Oil Chem. Soc. 82, 609-612.

Kuk M, Hron R J. 1998. Cottonseed extraction with new solvent system: Isohexane and alcohol. J. Am. Oil Chem. Soc. 75, 927-930.

List GR, Friedrich JP, Pominski J. 1984. Characterization and Processing of Cottonseed Oil Obtained by Extraction with Supercritical Carbon Dioxide, J. Am. Oil Chem. Soc. 61 1857-1849.

Lusas EW, Watkins LR, Koseoglu SS. 1991. Isopropyl alcohol to be tested as solvent. Inform. 2, 970-976.

Liauw MY, Natan FA, Widianti P, Iksari D, Indraswati $\mathrm{N}$, and Soetaredjo FE. 2008. Extraction of neem oil using n-hexane and ethanol: studies on oil quality, kinetic \& thermodynamics. ARPN J. Eng. Appl. Sci. 3,49-54.

Meziane S, Kadi H, Lamrous O. 2006. Kinetic study of oil extraction from olive foot cake. Grasasy Aceites 57, $175-179$
Meziane S, Kadi H. 2008. Kinetics and thermodynamics of oil extraction from olive cake. J. Am. Oil Chem. Soc. 85, 391-396.

$\mathrm{NIOSH}$ (2007). NIOSH pocket guide to chemical hazards, National Institute for Occupational Safety and Health , www.cdc.gov/niosh/npg/pdfs/2005-149.pdf.

PFA Act. 1954. Prevention of Food Adulteration Act. No.37 of 1954: Part III, Rule No.5, APPENDIX B Definition and Standards of Quality, A.17.02 as amended till date www.lawbooksshop.com.

Rakotondramasy RL, Havet JL, Porte C, Fauduet $\mathrm{H}$. 2007. Solid-liquid extraction of protopine from fumaria officinalis L-Analysis determination, kinetic reaction and model building. Sep.Purification Technol. 54, 253-261.

Sepidar S, Zurina ZA, Yunus R, Muhammad A. 2009. Extraction of Oil from Jatropha Seeds-Optimization and Kinetics. Am. J.Appl. Sci. 6, 1390-1395.

Seth S, Agrawal YC, Ghosh PK, Jayas DS, Singh BPN. 2007. Oil extraction rates of soya bean using isopropyl alcohol as solvent. Bioststems Eng. 97, 209-217.

Shekhar GC. 2006. India second largest global cotton producer, The Hindu, businessline.com, Wednesday, 2006/10/04.

Sineiro J, Domínguez H, Núñez MJ, Lema JM 1998. Ethanolic extraction of sunflower oil in a pulsing extractor. J. Am. Oil Chem. Soc. 75, 753-754.

Wan PJ, Pakarinen DR, Hron RJ, Richard OL, Conkerton EJ. 1995(a). Alternative hydrocarbon solvents for cottonseed extraction. J. Am. Oil Chem. Soc. 72, 653659

Wan PJ, Hron RJ, Dowd MK, Kuk MS, Conkerton EJ. 1995(b). Alternative hydrocarbon solvents for cottonseed extraction: plant trials. J. Am. Oil Chem. Soc. 72, 661-664.

Wenjuan Q, Zhongli P, Haile M. 2010. Extraction modeling and activities of antioxidants from pomegranate marc. J. Food Eng. 99, 16-23.

Wiese KL, Snyder HE. 1987. Analysis of the oil extraction process in soybeans: A new continuous procedure. J. Am. Oil Chem. Soc. 64, 402-406.

Recibido: 25/8/10 Aceptado: 20/10/10 